\title{
Transparência no Processo de Software como Apoio à Publicidade da Administração Pública
}

\author{
Fabíola Ferreira de Macedo ${ }^{1,2}$, Patrícia Vilain ${ }^{1}$ \\ ${ }^{1}$ Departamento de Informática e Estatística (INE) - Universidade Federal de Santa \\ Catarina (UFSC) \\ ${ }^{2}$ Assembleia Legislativa do Estado de Santa Catarina (ALESC) \\ ffm6325ealesc.sc.gov.br, vilaineinf.ufsc.br
}

\begin{abstract}
This paper explores the concepts of transparency in the process of software development to support publicity in public institutions. It consists of an analysis of the characteristics of transparency and a strategy that suggests practices to make the software development more transparent. The group of suggested practices emphasizes requirements gathering and focuses on outsourcing of software development in the public sector. The study was conducted based on the activities of the area of software development projects of the Legislative Assembly of the State of Santa Catarina (ALESC).
\end{abstract}

Resumo. Este trabalho explora os conceitos da transparência no processo de desenvolvimento de software a fim de apoiar a publicidade em instituições públicas. Ele consiste em uma análise das características de transparência e uma proposta de estratégia que sugere práticas para tornar o desenvolvimento de software mais transparente. O conjunto de práticas sugerido tem ênfase no levantamento de requisitos e é voltado à terceirização do desenvolvimento de software no setor público. O trabalho foi realizado baseando-se nas atividades da área de desenvolvimento de projetos de software da Assembleia Legislativa do Estado de Santa Catarina (ALESC).

\section{Introdução}

As sociedades democráticas atuais estão cada vez mais exigentes quanto à transparência e eficiência dos atos da administração pública. De acordo com Holzner (2006), a transparência é cada vez mais exigida no contexto global por causa da necessidade de se criar confiança entre vastas distâncias geográficas e culturais do mundo. Serrano e Leite (2011) consideram que a transparência é a base fundamental para estabelecer a confiança entre os cidadãos e seus governos.

Para Fung et al. (2007) o sucesso da transparência depende da compreensão dos tipos de problemas a serem abordados por meio da divulgação da informação. A literatura mostra que mesmo dentro de diferentes contextos, a ideia de transparência é sempre associada à divulgação e partilha de informação, e que esta se baseia em processos formais e padronizados de divulgação de informações (Vaccaro e Madsen, 2009). Assim, para Leite (2006) a engenharia de software deverá prover métodos, técnicas e ferramentas para auxiliar os engenheiros a produzir software mais transparente.

Nesse contexto, este trabalho aborda os conceitos e características relacionados à transparência e sugere uma estratégia que apresenta um conjunto de práticas para tornar 
o processo de desenvolvimento de software mais transparente. A estratégia proposta tem ênfase na fase de levantamento de requisitos e é voltada à terceirização do desenvolvimento de software no setor público. O objetivo é incluir mais transparência no processo de desenvolvimento de software para apoiar o processo de terceirização e dar mais publicidade às instituições públicas. O trabalho foi realizado em conjunto com a Assembleia Legislativa do Estado de Santa Catarina (ALESC), baseando-se nas suas atividades da área de desenvolvimento de projetos de software.

O artigo está organizado da seguinte forma. A seção 2 apresenta conceitos e definições para auxiliar o entendimento sobre transparência, características da transparência organizacional e operacionalizações de transparência. A seção 3 propõe uma estratégia inicial para incluir transparência nas organizações públicas. A seção 4 descreve as características da organização estudada, o seu processo de desenvolvimento e as características de transparência presentes no processo atual. Já a seção 5 traz uma explanação sobre as considerações finais.

\section{Conceitos e Definições}

No entendimento de Cappelli (2009), não é suficiente para uma organização desejar ser transparente, é preciso saber o que é transparência e como é possível inserir este conceito no negócio.

\subsection{Contextos da Transparência}

Tendo como principal plano de fundo as ciências sociais, no entendimento de Leite e Cappelli (2010), existem três diferentes níveis de transparência: a transparência social, a transparência alvo e a transparência organizacional. Enquanto a transparência social concentra-se nos cidadãos, a transparência alvo visa aos consumidores de bens ou serviços, e a transparência organizacional tem seu foco nas atividades da organização em relação às partes interessadas. Para Leite e Cappelli (2010), a transparência de software tem de lidar com esses diferentes contextos a fim de possibilitar aos cidadãos o acesso à informação e a processos mais transparentes.

Como o objetivo desse trabalho é incluir transparência no processo de desenvolvimento de software, é dada ênfase as atividades que visam estabelecer a transparência das políticas, padrões e procedimentos desse processo e, segundo Cappelli (2009), essas atividades se traduzem na transparência organizacional.

\subsection{Características de Transparência Organizacional}

De acordo com Cappelli e Leite (2008), a transparência do processo organizacional pode ser definida como a "existência de políticas organizacionais que visam fornecer aos interessados informações sobre a organização segundo características gerais de acesso, uso, apresentação, entendimento e usabilidade". Assim, segundo Cappelli (2009), a Transparência Organizacional pode ser definida por meio da Transparência do Processo e Transparência da Informação.

Para compor os processos e informações organizacionais a fim de fazê-los mais transparentes, o conjunto de características de transparência pode ser agrupado, a partir da organização proposta por Cappelli (2009), em: acessibilidade, sendo a transparência realizada por meio da capacidade de acesso; usabilidade, onde a transparência é alcançada por meio de facilidades de usos; informativo, em que a transparência é 
concretizada por meio da qualidade da informação; entendimento, tendo a transparência realizada por meio do entendimento; e auditabilidade, onde a transparência é realizada por meio da auditabilidade.

No entendimento de Araújo et al. (2010), "para se obter transparência, no sentido mais completo, todas estas características devem estar presentes na organização". Porém, os autores Leite e Cappelli (2010), alertam para o fato de que estas são características de qualidade, podendo existir diferentes níveis de entendimento e percepção dependendo do interessado. Para que a transparência dos processos organizacionais possam ser implementadas é necessário que as organizações definam que mecanismos utilizar para suas operacionalizações.

\subsection{Operacionalizações de Transparência}

As operacionalizações de transparência são iniciativas para incluir características de qualidade no contexto das organizações. Essas operacionalizações, de acordo com Cappeli (2009), são representadas pelas políticas, padrões e procedimentos que buscam estabelecer transparência durante a execução de processos de geração de informação na organização. Uma estrutura que auxilia na organização das características de qualidade é o Softgoal Interdependency Graph (SIG), um grafo proposto no framework NFR (Non-Funcional Requirement), definido por Chung (Chung, 2000 apud Cappelli, 2009), que propõe uma maneira sistematizada de decompor os requisitos não funcionais e organizar, operacionalizar e abordar as interdependências entre eles. A partir desse grafo e de atributos de transparência, Cappelli (2009) propôs o SIG de Transparência (Figura 1), que apresenta a priorização e as dependências entre as características de transparência, e as contribuições entre essas características definidas pelos conectores.

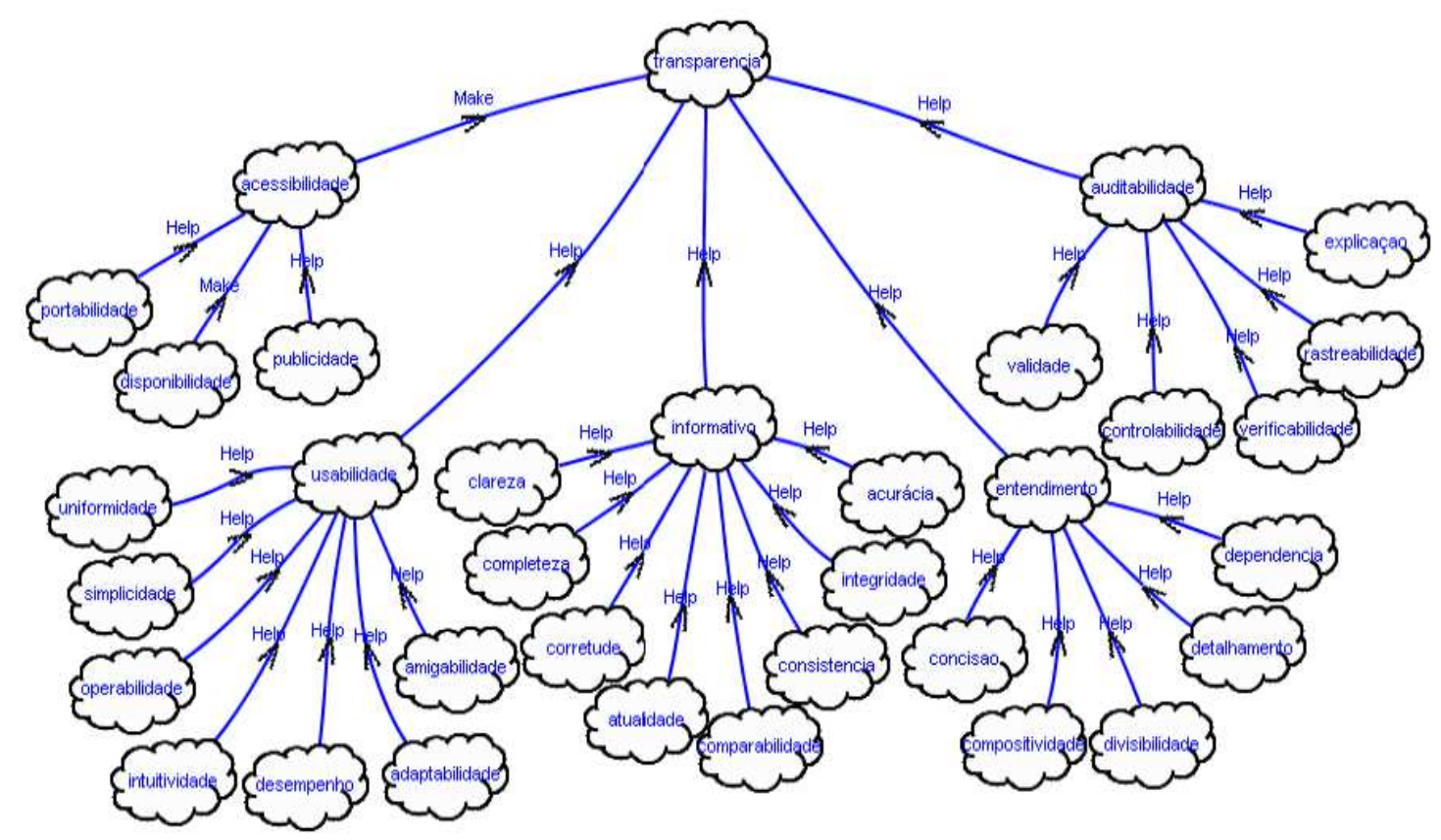

Figura 1. O SIG de Transparência - Versão Final (CAPPELLI, 2009).

Uma operacionalização é uma ação a ser executada para que um elemento do grafo seja incluído na organização (Cappelli, 2009). O conjunto de operacionalizações para inserir a transparência nas organizações gera como resultado um Catálogo de 
Transparência (Webster, 2005), que indica alternativas para o implementação dessas práticas.

\section{Incluindo Transparência nas Organizações Públicas}

Uma estratégia para incluir transparência no processo de desenvolvimento de software em organizações públicas é apresentada a seguir. A ideia é definir como os requisitos de transparência podem ser incluídos no processo de desenvolvimento de software que serão executados e nos editais de licitação que resultarão em contratos com empresas terceirizadas. A estratégia inicial sugere etapas com atividades a serem executadas durante os processos licitatórios e o detalhamento da fase de levantamento dos requisitos.

\subsection{Etapas do Processo Licitatório}

No contexto deste trabalho, o processo licitatório engloba as atividades que vão conduzir a aquisição de um software pela organização pública (contratante), desde o estabelecimento das necessidades (requisitos) até a aceitação do sistema entregue. Para conduzir as atividades do processo licitatório sugerem-se as etapas apresentadas na Figura 2. Trata-se de passos gerais que buscam prever e descrever as necessidades de aquisição como, por exemplo, o levantamento de requisitos com as características de transparência desejadas, a consulta das previsões legais, as auditorias quanto às operacionalizações exigidas e os critérios de aceitação.

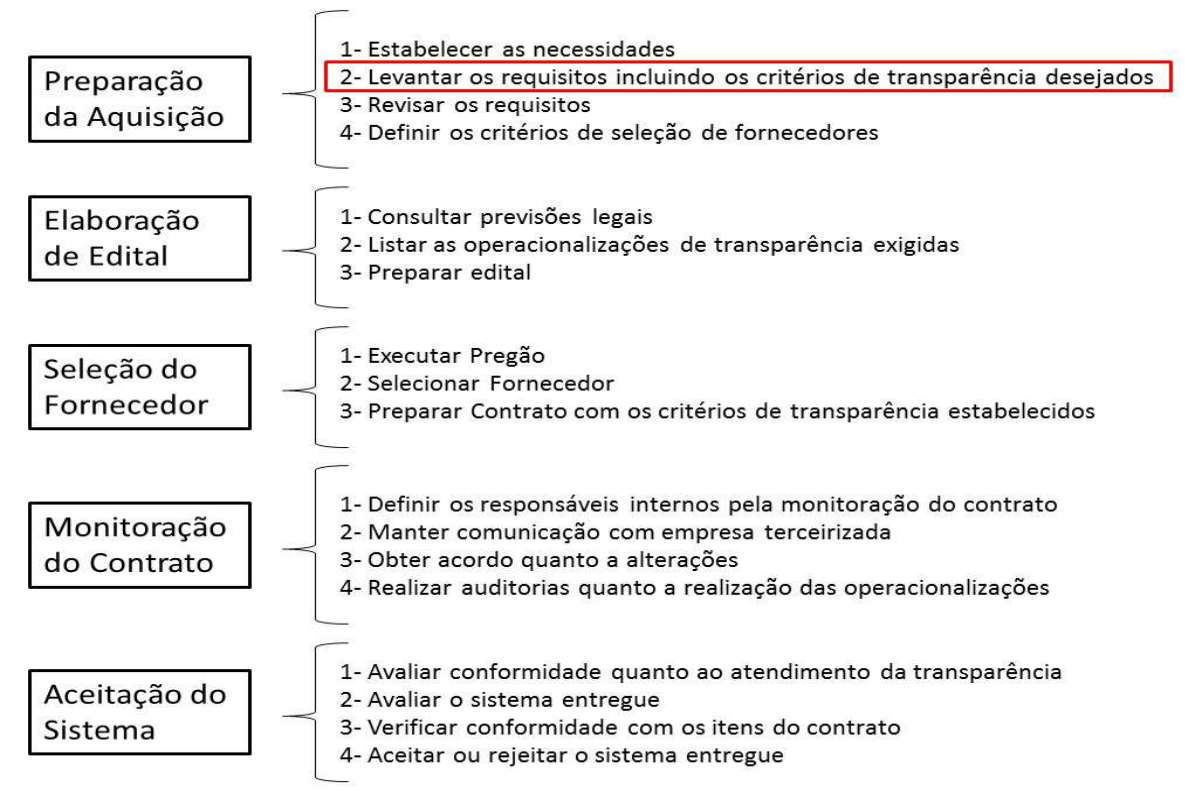

Figura 2. Etapas e atividades sugeridas para condução do processo licitatório Baseado no processo de aquisição de S\&SC (SOFTEX, 2009).

A sugestão dessas etapas e de suas atividades teve como base o processo de licitação atual da organização onde este trabalho está sendo aplicado (ver seção 4.2.), as atividades definidas pelo processo de aquisição de software e serviços correlatos (SOFTEX, 2009), e um conjunto de atividades que, segundo a opinião da equipe de analistas da organização, um processo licitatório deveria ter para auxiliar a inclusão de transparência no processo de desenvolvimento. Alguns exemplos das atividades propostas pela equipe são levantar os requisitos incluindo os critérios de transparência 
desejada, preparar contrato com os critérios estabelecidos para transparência, listar as operacionalizações exigidas para transparência, definir os responsáveis internos pela monitoração do contrato e realizar auditorias quanto à realização das operacionalizações.

Nas empresas que terceirizam o desenvolvimento de software, como comumente ocorre em instituições públicas, normalmente, o levantamento de requisitos é uma etapa do processo de desenvolvimento que é realizada pela empresa contratante antes de iniciar a elaboração do edital. Como a ênfase é na terceirização do desenvolvimento de software, o foco desta proposta inicial de estratégia é a atividade de levantamento de requisitos, destacada em vermelho na Figura 2. Portanto, faz-se necessário definir ações que colaborem para a transparência no processo de levantamento de requisitos.

\subsection{Transparência no Processo de Levantamento de Requisitos}

Para estabelecer quais as ações de apoio a transparência a serem incluídas no processo de levantamento de requisitos, realizou-se uma revisão em fontes que tratavam sobre o tema da transparência de software. A seleção das fontes, com as possíveis propostas para as operacionalizações de transparência, foi realizada conforme as seguintes características: (i) apresentar similaridade no conceito de transparência, (ii) possuir agrupamentos das operacionalizações segundo graus de transparência, (iii) fazer parte de estudos recentes (publicações entre 2006 e 2012). Em decorrência dessa revisão obteve-se a seleção de duas fontes: o relatório de atributos de transparência do Grupo de Engenharia de Requisitos PUC-Rio (Wiki, 2011) e o Catálogo de Transparência proposto por Cappelli (2009).

Posteriormente, realizou-se a seleção das operacionalizações presentes nessas duas fontes, elegendo para compor o processo de levantamento de requisitos aquelas que atendiam os seguintes critérios de inclusão: constar como atividades do processo licitatório em instituições públicas (sugeridas na seção 3.1); e/ou, serem consideradas importantes pela equipe de desenvolvimento da organização estudada. Sendo este último critério verificado por meio de pesquisa descritiva realizada numa amostra de dez profissionais da área de desenvolvimento. Obteve-se como resultado desse processo a listagem das operacionalizações de transparência para o processo de levantamento de requisitos apresentadas na Tabela 1.

Os atributos relacionados (Tabela 1) estão organizados por "graus de transparência" conforme classificação proposta por Cappelli (2009). As operacionalizações, por sua vez, são iniciativas para incluir as características de qualidade na fase de levantamento de requisitos. Elas são necessárias para melhorar a visão sobre o processo de desenvolvimento, identificando, padronizando e controlando as ações que produziram as informações, visando aumentar o conhecimento sobre o mesmo, auxiliando em uma maior transparência.

Destaca-se que nem sempre todos esses itens precisam estar presentes em um projeto. Um exemplo são os sistemas de menor complexidade e que requerem um processo de software mais simples. Nesses casos, sugere-se priorizar os itens da lista de operacionalizações, dando preferência pela utilização das ações ligadas ao melhor cumprimento dos elementos do processo licitatório em questão. Ou seja, orienta-se priorizar as operacionalizações que influenciam diretamente as cláusulas contratuais e/ou de legislação relativas a cada projeto. 
Tabela 1. Operacionalizações de transparência para levantamento de requisitos

\begin{tabular}{|c|c|c|c|c|c|c|}
\hline $\begin{array}{c}\text { Graus de } \\
\text { Transparência }\end{array}$ & Atributos & Operacionalizações & $\begin{array}{l}\text { 음 } \\
\text { 을 } \\
\stackrel{2}{0} \\
\stackrel{1}{0}\end{array}$ & 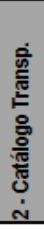 & 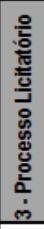 & 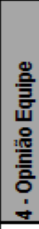 \\
\hline Usabilidade & Operabilidade & Descrever os objetivos do processo & & $\mathrm{x}$ & $\mathrm{x}$ & $\mathrm{x}$ \\
\hline Usabilidade & Operabilidade & Descrever principais funções do sistema & & $\mathrm{x}$ & $\mathbf{x}$ & $\mathbf{x}$ \\
\hline Usabilidade & Uniformidade & Utilizar padrões de desenvolvimento & $\mathrm{x}$ & $\mathrm{x}$ & & $\mathrm{x}$ \\
\hline Usabilidade & Uniformidade & Definir os termos do domínio & & $\mathrm{x}$ & $\mathrm{x}$ & $\mathrm{x}$ \\
\hline Usabilidade & Amigabilidade & Usar representação gráfica para melhor entedimento do processo & & $\mathbf{x}$ & & $\mathrm{x}$ \\
\hline Usabilidade & Amigabilidade & Oferecer informações sobre as atividades a serem executadas & & $\mathrm{x}$ & $\mathrm{x}$ & $\mathrm{x}$ \\
\hline Usabilidade & Amigabilidade & Usar recomendações ergonômicas para IHC & $\mathrm{x}$ & $\mathrm{x}$ & & $\mathrm{x}$ \\
\hline Usabilidade & Simplicidade & Utilizar padrões de documentos & $\mathrm{x}$ & $\mathrm{x}$ & & $\mathrm{x}$ \\
\hline Usabilidade & Simplicidade & Unificar as fontes de informação & & $\mathrm{x}$ & & $\mathrm{x}$ \\
\hline Usabilidade & Intuitividade & Utilizar os termos pertencentes ao domínio & $\mathrm{x}$ & & & $\mathrm{x}$ \\
\hline Usabilidade & Intuitividade & Promover o reconhecimento facilitado dos padrões & $\mathrm{x}$ & $\mathrm{x}$ & $\mathrm{x}$ & \\
\hline Usabilidade & Adaptabilidade & Permitir mudanças de processo, atividades ou fluxo & & $\mathbf{x}$ & $\mathbf{x}$ & \\
\hline Usabilidade & Desempenho & Definir requisitos de desempenho do sistema & $\mathrm{x}$ & & $\mathrm{x}$ & $\mathrm{x}$ \\
\hline Auditabilidade & Validade & Testar se processos atendem aos objetivos definidos & & $\mathbf{x}$ & $\mathrm{x}$ & \\
\hline Auditabilidade & Controlabilidade & Registrar decisões tomadas & & $\mathrm{x}$ & $\mathrm{x}$ & $\mathrm{x}$ \\
\hline Auditabilidade & Controlabilidade & Definir pontos de controle & $\mathbf{x}$ & $\mathrm{x}$ & $\mathrm{x}$ & \\
\hline Auditabilidade & Controlabilidade & Conferir e Registrar a execução das tarefas & & $\mathrm{x}$ & $\mathrm{x}$ & \\
\hline Auditabilidade & Verificabilidade & Verificar se o que está sendo feito é o correto & & $\mathrm{x}$ & $\mathrm{x}$ & \\
\hline Auditabilidade & Rastreabilidade & Manter o histórico de alterações & $\mathbf{x}$ & $\mathbf{x}$ & $\mathbf{x}$ & \\
\hline Auditabilidade & Rastreabilidade & Identificar requisitos de software por atividades & & $\mathrm{x}$ & & $\mathrm{x}$ \\
\hline Auditabilidade & Rastreabilidade & Identificar os motivos das alterações & & $\mathrm{x}$ & $\mathrm{x}$ & \\
\hline Auditabilidade & Rastreabilidade & Identificar os responsáveis pelas alterações & & $\mathrm{x}$ & $\mathrm{x}$ & \\
\hline Auditabilidade & Rastreabilidade & Permitir consulta ao histórico das atividades & & $\mathbf{x}$ & $\mathrm{x}$ & $\mathrm{x}$ \\
\hline Auditabilidade & Explicação & Identificar e Justificar as ações e atividades & & $\mathbf{x}$ & & $\mathrm{x}$ \\
\hline Acessibilidade & Portabilidade & Utilizar linguagens e padrões abertos & $\mathbf{x}$ & & & $\mathrm{x}$ \\
\hline Acessibilidade & Portabilidade & Permitir execução em diferentes plataformas & $\mathbf{x}$ & $\mathrm{x}$ & $\mathrm{x}$ & \\
\hline Acessibilidade & Disponibilidade & Disponibilizar as informações por meio de Sistemas de Informação & $\mathrm{x}$ & $\mathrm{x}$ & & $\mathrm{x}$ \\
\hline Acessibilidade & Publicidade & Divulgar cronograma de desenvolvimento & & $\mathbf{x}$ & $\mathrm{x}$ & $\mathrm{x}$ \\
\hline Acessibilidade & Publicidade & Disponibilizar documentação permitindo reuso & & $\mathrm{x}$ & & $\mathrm{x}$ \\
\hline Entendimento & Dependência & Identificar composição e relações entre informações & $\mathbf{x}$ & $\mathrm{x}$ & $\mathrm{x}$ & \\
\hline Entendimento & Dependência & Identificar recursos por atividades & & $\mathrm{x}$ & $\mathbf{x}$ & \\
\hline Entendimento & Divisibilidade & Identificar as regras de formação de processos & $\mathrm{x}$ & $\mathrm{x}$ & $\mathbf{x}$ & \\
\hline Entendimento & Divisibilidade & Possibilitar o particionamento de processos e informações & & $\mathbf{x}$ & & $\mathbf{x}$ \\
\hline Entendimento & Concisão & Criar versões resumidas das informações & & $\mathrm{x}$ & & $\mathrm{x}$ \\
\hline Informativo & Clareza & Identificar as regras utilizadas (negócio, legislação) & $\mathbf{x}$ & & $\mathbf{x}$ & $\mathrm{x}$ \\
\hline Informativo & Clareza & Descrever e detalhar os processos e atividades & & $\mathrm{x}$ & & $\mathrm{x}$ \\
\hline Informativo & Consistência & Comparar os objetivos com os resultados alcançados & & $\mathrm{x}$ & $\mathrm{x}$ & $\mathrm{x}$ \\
\hline Informativo & Integridade & Apresentar as fontes de informação & & $\mathbf{x}$ & & $\mathrm{x}$ \\
\hline Informativo & Corretude & Possuir atividades para cumprir as leis que regem o processo & $\mathbf{x}$ & $\mathrm{x}$ & $\mathbf{x}$ & $\mathrm{x}$ \\
\hline Informativo & Corretude & Possuir atividades para cumprir as regras da organização & $\mathbf{x}$ & $\mathbf{x}$ & $\mathbf{x}$ & $\mathbf{x}$ \\
\hline Informativo & Acurácia & Controlar possíveis erros sistemáticos & & $\mathrm{x}$ & & $\mathrm{x}$ \\
\hline Informativo & Acurácia & Verificar se os resultados atendem aos objetivos & & $\mathbf{x}$ & $\mathbf{x}$ & $\mathrm{x}$ \\
\hline Informativo & Atualização & Permitir controle de versão & & $\mathbf{x}$ & & $\mathrm{x}$ \\
\hline Informativo & Completeza & Verificar se as atividades e processos atendem todos os objetivos & $\mathrm{x}$ & $\mathrm{x}$ & $\mathbf{x}$ & $\mathbf{x}$ \\
\hline Informativo & Comparabilidade & Definir padrões que permitam a comparação entre planejado e executado & $\mathrm{x}$ & $\mathrm{x}$ & $\mathrm{x}$ & $\mathrm{x}$ \\
\hline
\end{tabular}

Observa-se, em relação à Tabela 1, que as operacionalizações que mais vezes foram marcadas como necessárias ao processo licitatório, são aquelas ligadas aos graus de usabilidade, auditabilidade e informativo, e, portanto, poderiam ser consideradas as mais influentes para a transparência nesse contexto. As operacionalizações definidas para o grau de usabilidade preveem ações para melhorar a definição de objetivos e funções, a padronização, a diminuição do esforço, a simplificação das atividades, o uso da intuitividade e a definição de requisitos de desempenho. As ações ligadas ao grau de auditabilidade visam permitir o rastreamento, o controle, a validação e a explicação do sistema. Já as operacionalizações ligadas ao grau informativo permitem identificar as regras de negócio e legislação, em comparação aos objetivos e aos resultados alcançados. 
Discorre-se que a maioria das operacionalizações listadas, de certa forma, já é usualmente prevista em processos de desenvolvimento ou em modelos de qualidade de processos amplamente conhecidos na indústria. A principal diferença decorre da importância dada ao cumprimento do atendimento legal do processo de licitação e das ações vinculadas à maior publicidade, primordiais para instituições públicas. Dessa forma as empresas terceirizadas, quando contratadas por órgãos públicos, têm autonomia para continuar utilizando os modelos e processos já implantados em sua estrutura, apenas adaptando-os para atender as exigências contratuais.

Sugere-se assim, que o conjunto das operacionalizações (Tabela 1) seja incluído no processo de levantamento de requisitos, tornando o processo de desenvolvimento mais transparente ao inserir, em sua fase inicial, ações que contribuam para inclusão de características de transparência no processo da contratante, ou seja, a instituição pública que realiza o levantamento de requisitos. Ainda, como apoio, a fim de facilitar a comprovação do atendimento, por parte das empresas terceirizadas, aos requisitos do sistema entregue e aos critérios de transparência que possam ser pré-estabelecidos em contrato (para as outras fases do desenvolvimento), sugere-se que algumas dessas operacionalizações sejam incluídas em um checklist de verificação (Tabela 2), a ser utilizado na etapa de aceitação do sistema.

Tabela 2. Checklist de verificação de conformidade com contrato

\begin{tabular}{|c|c|c|c|}
\hline $\begin{array}{c}\text { Graus de } \\
\text { Transparência }\end{array}$ & Atributos & Operacionalizaçöes & \\
\hline Usabilidade & Uniformidade & Utilizar padrões de desenvolvimento & \\
\hline Usabilidade & Amigabilidade & Oferecer informações sobre as atividades a serem executadas & \\
\hline Usabilidade & Amigabilidade & Usar recomendações ergonômicas para IHC & \\
\hline Usabilidade & Simplicidade & Utilizar padrões de documentos & \\
\hline Usabilidade & Intuitividade & Utilizar os termos pertencentes ao domínio & \\
\hline Usabilidade & Intuitividade & Promover o reconhecimento facilitado dos padrões & \\
\hline Auditabilidade & Validade & Testar se processos atendem aos objetivos definidos & \\
\hline Auditabilidade & Verificabilidade & Verificar se o que está sendo feito é o correto & \\
\hline Auditabilidade & Rastreabilidade & Manter o histórico de alteraç̃es & \\
\hline Auditabilidade & Rastreabilidade & Identificar requisitos de software por atividades & \\
\hline Auditabilidade & Rastreabilidade & Identificar os motivos das alterações & \\
\hline Auditabilidade & Rastreabilidade & Identificar os responsáveis pelas alterações & \\
\hline Auditabilidade & Rastreabilidade & Permitir consulta ao histórico das atividades & \\
\hline Acessibilidade & Portabilidade & Utilizar linguagens e padrões abertos & \\
\hline Acessibilidade & Portabilidade & Permitir execução em diferentes plataformas & \\
\hline Acessibilidade & Disponibilidade & Disponibilizar as informações por meio de Sistemas de Informação & \\
\hline Acessibilidade & Publicidade & Divulgar cronograma de desenvolvimento & \\
\hline Acessibilidade & Publicidade & Disponibilizar documentação permitindo reuso & \\
\hline Entendimento & Dependência & Identificar recursos por atividades & \\
\hline Entendimento & Concisão & Criar versões resumidas das informações & \\
\hline Informativo & Consistência & Comparar os objetivos com os resultados alcançados & \\
\hline Informativo & Integridade & Apresentar as fontes de informação & \\
\hline Informativo & Acurácia & Verificar se os resultados atendem aos objetivos & \\
\hline Informativo & Atualização & Permitir controle de versão & \\
\hline Informativo & Completeza & Verificar se as atividades e processos atendem todos os objetivos & \\
\hline Informativo & Comparabilidade & Definir padrões que permitam a comparação entre planejado e executado & \\
\hline
\end{tabular}

As operacionalizações escolhidas para constituir o checklist de verificação são aquelas que visam permitir a verificação da conformidade com os itens estabelecidos em contrato, facilitando para a empresa contratante a aceitação ou rejeição do sistema entregue pela empresa terceirizada. Elas foram selecionadas dentre as operacionalizações apresentadas anteriormente (Tabela 1), empregando aquelas que têm a possibilidade de serem verificadas de maneira direta, ou seja, por meio do software ou documentação como, por exemplo, "usar recomendações ergonômicas para IHC". E ainda, excluindo aquelas que já são realizadas na fase de levantamento de requisitos e não precisam de continuidade nas demais fases de desenvolvimento como, por exemplo, "descrever os objetivos do processo". 
Esse checklist poderia ser utilizado também durante a fase de monitoração de contrato para apoiar atividades de auditorias quanto à realização das operacionalizações, permitindo avaliar a conformidade com o contrato também durante o desenvolvimento do sistema e não apenas quando o software é entregue.

\section{Estudo de Caso: Análise da Transparência em uma Organização Pública}

Nessa seção são apresentadas algumas características da organização estudada, a descrição do seu processo de desenvolvimento de software e a verificação de características de transparência existentes atualmente.

\subsection{Características da Organização}

A organização em estudo é uma instituição pública, a Assembleia Legislativa do Estado de Santa Catarina (ALESC), e deve, portanto, atender, entre outros, ao princípio constitucional de publicidade. A publicidade é a obrigação de levar ao conhecimento público os atos da administração, conferindo transparência às atividades da instituição (Brasil, 1988 e Brasil, 2009).

A área responsável pelos sistemas computacionais da ALESC é a Diretoria de Tecnologia de Informação e Comunicação e dentro desta Diretoria está a Coordenadoria de Projetos e Desenvolvimento que, por meio da sua Gerência de Projetos e Desenvolvimento, é responsável pelos projetos de desenvolvimento e manutenção dos sistemas de software, bem como do controle gerencial desses projetos. A Gerência de Projetos e Desenvolvimento conta com uma equipe de servidores efetivos para desenvolvimento de projetos de software, mas também, devido a grande demanda, contrata serviços de desenvolvimento de empresas terceirizadas por meio de processos licitatórios.

\subsection{Processo de Desenvolvimento de Software na Organização}

A organização tem definido um modelo de processo de desenvolvimento de software que orienta a abordagem e os passos a serem executados durante a elaboração e execução dos projetos. O modelo em questão é composto pelas fases de Visão do Sistema, Levantamento de Requisitos, Modelagem, Projeto, Implementação, Testes, Validação e Implantação. Entretanto, nem sempre o desenvolvimento de um sistema segue todas essas fases dentro da própria organização, pois devido à alta demanda por sistemas de informação, muitas vezes é essencial a terceirização de algumas dessas etapas. Atualmente, quando o desenvolvimento de um software é terceirizado, das fases iniciais, apenas a fase de Visão do Sistema é executada pela própria instituição. Ou seja, todas as outras fases, desde o levantamento de requisitos até os testes, são realizadas pela empresa terceirizada, dificultando assim a elaboração dos contratos, o controle e a validação e verificação do sistema.

E como ocorre com todas as empresas públicas, é obrigatória a realização de licitação para a contratação de serviços para desenvolvimento de sistemas, ou terceirização de serviços. As licitações no Brasil são regulamentadas pela Lei 8.666/93 (Brasil, 1993), que institui as normas para contração dos serviços e objetiva classificar a empresa fornecedora que oferece a proposta mais vantajosa. Na organização estudada, o processo de licitação para desenvolvimento de sistemas prevê as etapas de Elaboração de Edital, que dá maior ênfase aos requisitos técnicos, de Realização de Pregão, que tem 
foco no atendimento às previsões legais e a de Aceitação do Sistema, que visa verificar o atendimento aos critérios estabelecidos.

\subsection{Características de Transparência Presentes no Processo Atual}

Uma possível abordagem para identificar a aderência da transparência na organização é comparar as ações definidas para inclusão de transparência com as características de transparência que o processo atual satisfaz. Assim, um comparativo foi realizado com base na observação do processo atual, verificando, além das evidências documentais, a opinião especializada dos analistas de desenvolvimento da organização (Tabela 3).

Tabela 3. Operacionalizações de transparência atendidas pelo processo atual

\begin{tabular}{|c|c|c|c|}
\hline $\begin{array}{c}\text { Graus de } \\
\text { Transparência }\end{array}$ & Atributos & Operacionalizações & Atendida pelo Processo Atual? \\
\hline Usabilidade & Operabilidade & Descrever os objetivos do processo & Prevista e totalmente executada \\
\hline Usabilidade & Operabilidade & Descrever principais funções do sistema & Prevista e totalmente executada \\
\hline Usabilidade & Uniformidade & Utilizar padrões de desenvolvimento & Prevista, mas parcialmente executada \\
\hline Usabilidade & Uniformidade & Definir os termos do domínio & Prevista, mas parcialmente executada \\
\hline Usabilidade & Amigabilidade & Usar representação gráfica para melhor entedimento do processo & Prevista, mas parcialmente executada \\
\hline Usabilidade & Amigabilidade & Oferecer informações sobre as atividades a serem executadas & Prevista, mas parcialmente executada \\
\hline Usabilidade & Amigabilidade & Usar recomendações ergonômicas para IHC & Não prevista \\
\hline Usabilidade & Simplicidade & Utilizar padrões de documentos & Prevista, mas não executada \\
\hline Usabilidade & Simplicidade & Unificar as fontes de informação & Não prevista \\
\hline Usabilidade & Intuitividade & Utilizar os termos pertencentes ao domínio & Prevista, mas parcialmente executada \\
\hline Usabilidade & Intuitividade & Promover o reconhecimento facilitado dos padrões & Não prevista \\
\hline Usabilidade & Adaptabilidade & Permitir mudanças de processo, atividades ou fluxo & Prevista e totalmente executada \\
\hline Usabilidade & Desempenho & Definir requisitos de desempenho do sistema & Não prevista \\
\hline Auditabilidade & Validade & Testar se processos atendem aos objetivos definidos & Prevista, mas parcialmente executada \\
\hline Auditabilidade & Controlabilidade & Registrar decisões tomadas & Prevista, mas parcialmente executada \\
\hline Auditabilidade & Controlabilidade & Definir pontos de controle & Não prevista \\
\hline Auditabilidade & Controlabilidade & Conferir e Registrar a execução das tarefas & Não prevista \\
\hline Auditabilidade & Verificabilidade & Verificar se o que está sendo feito é o correto & Prevista, mas parcialmente executada \\
\hline Auditabilidade & Rastreabilidade & Manter o histórico de alterações & Prevista, mas parcialmente executada \\
\hline Auditabilidade & Rastreabilidade & Identificar requisitos de software por atividades & Não prevista \\
\hline Auditabilidade & Rastreabilidade & Identificar os motivos das alterações & Não prevista \\
\hline Auditabilidade & Rastreabilidade & Identificar os responsáveis pelas alterações & Não prevista \\
\hline Auditabilidade & Rastreabilidade & Permitir consulta ao histórico das atividades & Não prevista \\
\hline Auditabilidade & Explicação & Identificar e Justificar as ações e atividades & Não prevista \\
\hline Acessibilidade & Portabilidade & Utilizar linguagens e padrões abertos & Prevista, mas não executada \\
\hline Acessibilidade & Portabilidade & Permitir execução em diferentes plataformas & Não prevista \\
\hline Acessibilidade & Disponibilidade & Disponibilizar as informações por meio de Sistemas de Informação & Prevista, mas parcialmente executada \\
\hline Acessibilidade & Publicidade & Divulgar cronograma de desenvolvimento & Prevista, mas parcialmente executada \\
\hline Acessibilidade & Publicidade & Disponibilizar documentação permitindo reuso & Não prevista \\
\hline Entendimento & Dependência & Identificar composição e relações entre informações & Não prevista \\
\hline Entendimento & Dependência & Identificar recursos por atividades & Não prevista \\
\hline Entendimento & Divisibilidade & Identificar as regras de formação de processos & Prevista e totalmente executada \\
\hline Entendimento & Divisibilidade & Possibilitar o particionamento de processos e informações & Prevista, mas parcialmente executada \\
\hline Entendimento & Concisão & Criar versões resumidas das informações & Prevista, mas parcialmente executada \\
\hline Informativo & Clareza & Identificar as regras utilizadas (negócio, legislação) & Prevista e totalmente executada \\
\hline Informativo & Clareza & Descrever e detalhar os processos e atividades & Prevista, mas parcialmente executada \\
\hline Informativo & Consistência & Comparar os objetivos com os resultados alcançados & Prevista, mas parcialmente executada \\
\hline Informativo & Integridade & Apresentar as fontes de informaçãa & Prevista e totalmente executada \\
\hline Informativo & Corretude & Possuir atividades para cumprir as leis que regem o processo & Prevista e totalmente executada \\
\hline Informativo & Corretude & Possuir atividades para cumprir as regras da organização & Prevista e totalmente executada \\
\hline Informativo & Acurácia & Controlar possiveis erros sistemáticos & Prevista, mas parcialmente executada \\
\hline Informativo & Acurácia & Verificar se os resultados atendem aos objetivos & Prevista, mas parcialmente executada \\
\hline Informativo & Atualização & Permitir controle de versão & Prevista, mas parcialmente executada \\
\hline Informativo & Completeza & Verificar se as atividades e processos atendem todos os objetivos & Prevista, mas parcialmente executada \\
\hline Informativo & Comparabilidade & Definir padrões que permitam a comparação entre planejado e executado & Prevista, mas parcialmente executada \\
\hline
\end{tabular}


O comparativo apresentado na Tabela 3 mostra as operacionalizações definidas para o processo de levantamento de requisitos, vistas na seção 3.2, em relação ao atendimento dessas ações pelo processo atual da organização. Uma operacionalização foi considerada "Prevista e totalmente executada" quando a ação é prevista e executada de forma satisfatória, "Prevista, mas parcialmente executada" quando a ação é prevista, mas não é executada de forma satisfatória, "Prevista, mas não executada" quando a ação é prevista pela organização, mas não é executada, e "Não prevista" quando a ação não é prevista pela organização. A expressão "executada de forma satisfatória" significa que tudo que envolve a operacionalização é realizado.

Os percentuais de atendimento em relação a este resultado são apresentados na Figura 3, evidenciando que há necessidade de melhorias no processo de desenvolvimento de software visando uma maior transparência.

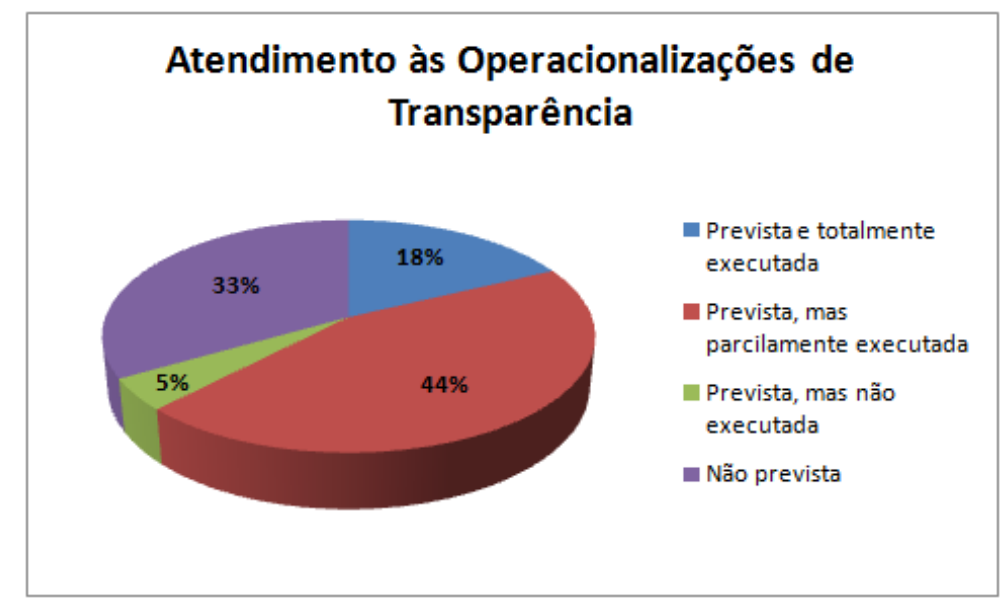

Figura 3. Percentuais de atendimento às operacionalizações de transparência na organização estudada.

Algumas sugestões de melhorias no processo para que as operacionalizações se tornem "Previstas e totalmente executadas" são, por exemplo, no caso da ação "Utilizar linguagens e padrões abertos", classificada atualmente como "Prevista, mas não executada", que sejam realizadas atividades para institucionalizar os padrões já definidos, o que poderia ser feito por meio de treinamentos, campanhas de mobilização e maior controle do processo. Ou ainda, no caso da operacionalização "Identificar os responsáveis pelas alterações", classificada como "Não Prevista", sugere-se a definição de um plano para que seja mantido o histórico dos responsáveis pelas mudanças, e que esse plano seja efetivamente executado, o que poderia ser feito com o auxílio de uma ferramenta de controle de alterações.

\section{Considerações Finais}

A sociedade cada vez mais discute o seu direito ao acesso às informações. Nesse sentido diversas iniciativas têm sido realizadas buscando a promoção da transparência, principalmente, no que diz respeito à publicidade dos atos da administração pública. Entretanto, para melhor disponibilização dessas informações é necessário compreender o que é a transparência e estabelecer mecanismos para incluí-las nas organizações.

Nesse contexto, este trabalho apresentou os conceitos da transparência de software com objetivo de incluir transparência no processo de desenvolvimento de software, com ênfase na fase de levantamento de requisitos, a fim de apoiar a 
publicidade em instituições públicas que terceirizam o desenvolvimento de sistemas. Uma análise das características de transparência foi realizada e a partir dela foi sugerida uma estratégia para tornar o ciclo de desenvolvimento de software mais transparente. Essa estratégia recomendou atividades a serem realizadas durante os processos licitatórios, listou algumas operacionalizações a serem executadas durante a fase de levantamento dos requisitos e propôs um checklist de verificação a ser utilizado na etapa de aceitação do sistema para facilitar a comprovação do atendimento da transparência por parte das empresas terceirizadas. Os elementos dessa estratégia podem, em princípio, serem reaproveitados em outras organizações contribuindo assim, para melhoria da transparência em projetos de outras instituições públicas.

Um estudo de caso foi realizado com base nas atividades da área de desenvolvimento de projetos de software da Assembleia Legislativa do Estado de Santa Catarina (ALESC), descrevendo seu processo de desenvolvimento e realizando um comparativo entre as ações para incluir características de transparência presentes no processo atual da organização e aquelas consideradas necessárias. A partir desse comparativo verificou-se que a maioria das ações consideradas necessárias (em torno de $80 \%$ ) não é plenamente atendida na organização estudada, evidenciando a necessidade de melhorias no processo.

Para modificar este quadro, sugere-se a utilização de alguma estratégia que permita avaliar e introduzir as características de transparência nos processos organizacionais, como por exemplo, aquelas propostas nos estudos de Cappelli (2009) ou Araújo et al. (2011). Cappelli (2009) apresenta uma abordagem orientada a aspectos que permite a introdução de características de transparência nos processos organizacionais por meio da construção de políticas e padrões, e, com apoio de um catálogo de transparência, a inserção de novos elementos nos modelos de processos organizacionais existentes. Araújo et al. (2010) mostra como um modelo de estágios pode ajudar gestores na implantação de programas de transparência e dá os primeiros passos para construção de um modelo para definir práticas para implementação das características de transparência e regras de avaliação sobre essas qualidades.

Com a introdução das características de transparência pretende-se tornar o processo de desenvolvimento na empresa onde o estudo de caso foi aplicado mais transparente, começando em sua fase inicial, a de levantamento de requisitos, e incluindo ações que contribuam para inserção dessas características. Essas mesmas ações podem ser inseridas nos editais de licitação como critérios exigidos para os requisitos de sistema, podendo ser incluídas nos contratos com as empresas terceirizadas. Finalmente, objetiva-se como trabalho futuro expandir a inclusão das características de transparência para as outras fases do processo englobando todo o ciclo de desenvolvimento de software.

\section{Referências Bibliográficas}

Araújo, R.M.,Cappelli, C. A., Leite, J.C.S.P. (2010). A importância de um Modelo de Estágios para avaliar Transparência. Revista TCMRJ, setembro, 2010. Número: 45, p. 97.

Brasil (1998). Constituição da República Federativa do Brasil. Brasília, DF, Senado,1998. 
Brasil (2009). Lei no 131, de 27 de maio de 2009. "Dispõe sobre disponibilização em tempo real de informações (Lei da Transparência)." Disponível em: https://www.planalto.gov.br/. Acesso em 26/11/2011.

Brasil (1993). Lei no 8.666, de 21 de junho de 1993. "Regulamenta o art.37, inciso XXI, da Constituição Federal, institui normas para licitações e contratos da Administração Pública e dá outras providências". 1993.

Cappelli, C. A., Leite, J.C.S.P. (2008). Transparência de Processos Organizacionais. Universidade Federal Fluminense, LATEC. II Simpósio Internacional de Transparência os Negócios. 2008.

Cappelli, C. A. (2009). Uma Abordagem para Transparência em Processos Organizacionais Utilizando Aspectos. 2009. 328p. Tese de Doutorado, Departamento de Informática, PUC-Rio, Rio Janeiro. 2009.

Fung, A., Graham, M., Weil, D., Fagotto E. (2007). Transparency policies: Two possible futures. Alfred Taubman center for state and local government, Kennedy School of Government, Harvard University.Taubman Policy Brief PB-2007-1.

Holzner, B., Holzner L. (2006). Transparency in Global Change: The Vanguard of the Open Society. University of Pittsburgh Press; 1 edition, 2006.

Leite, J. C. S. P. (2006). Sistemas de Software Transparentes. Palestra convidada do $20^{\circ}$ Simpósio Brasileiro de Engenharia de Software, Outubro 2006. Disponível em: http://www-di.inf.puc-rio.br/ julio/Slct-pub/transp-sbes.pdf. Acesso em: 15/11/2011.

Leite, J.C.S.P.,Cappelli, C. A. (2010). Sofware Transparency. Business \& Information Systems Engineering, Springer, 01 jun. 2010.Volume: 2, Número: 3, p. 127-139.

Serrano, M., Leite, J.C.S.P. (2011). Capturing Transparency-Related Requirements Patterns through Argumentation. Requirements Patterns (RePa).First International Workshop on, p.32-41, Aug. 2011. DOI: 10.1109/RePa.2011.6046723 2011.

SOFTEX (2009). Guia de Aquisição MPS. BR - Melhoria de Processo do Software Brasileiro. Brasília (DF), 2009. Disponível em: http://www.softex.br. Acesso em: 08/12/2011.

Vaccaro, A., Madsen, P. (2009). Corporate dynamic transparency: the new ICT-driven ethics? Ethics and Information Technology Journal. Springer Netherlands Computer Science,2009-06-01. pp. 113-122.Volume: 11. Url: http://dx.doi.org/10.1007/s10676009-9190-1. DOI: 10.1007/s10676-009-9190-1

Webster, I., Amaral, J.,Cysneiros, L.M. (2005). Reusable Knowledge for Achieving Privacy: A Canadian Health Information Technologies Perspective, In: Proceedings of Workshop in Requirements Engineering, pp112-122, Porto,Portugal, 2005.

WiKi (2011). Wiki do Grupo de Engenharia de Requisitos - PUC-RIO. Disponível em: http://www.er.les.inf.puc-rio.br/ wiki/index.php/Transparência_de_Software. Acesso em: 03/12/2011. 